\title{
The Influence of Prints Ageing on NuMBER AND SIZE OF INK PARTICLES IN THE PAPER ReCyCling Process
}

\author{
BolanCA Mirkovic, I. \& DragojeviC, M.
}

Abstract: Recycled fibres have become an important source in the paper production. In the deinking proces, the ink should first detach from the fibers, then ink and fibers separate from each other by flotation according to different surface properties. In this work the research results of the influence of the prints ageing on number and size of ink particles and the area they occupy on handsheet in different phases of the paper recycling process have been presented. Results are discussed in relation to prints from different printing techniques made with inks of different formulation.

The research results confirm the prints ageing influence on the size and the number of ink particles on handsheet from different phases of the paper recycling process in the function of the printing technique and the ink composition in the framework of experimental conditions. Weaker recycling effectiveness of the aged offset prints with the ink with the increased part of the renewable raw material has been observed in relation to other samples, which is explained by the oxidative processes.

Key words: offset prints, digital prints, ageing of prints, deinking flotation, image analysis, brightness
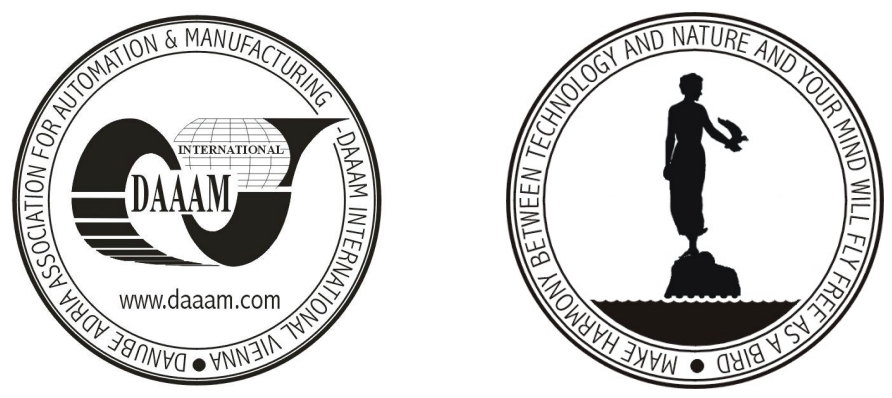

Authors' data: Bolanca Mirkovic I.[vana], Dragojevic M.[aja], Faculty of Graphic Arts, University of Zagreb, grfibolanca@yahoo.com, majadra@yahoo.com.

This Publication has to be referred as: Bolanca Mirkovic, I. \& Dragojevic, M. (2006). The Influence of Prints Ageing on Number and Size of Ink Particles in the Paper Recycling Process, Chapter 06 in DAAAM International Scientific Book 2006, B. Katalinic (Ed.), Published by DAAAM International, ISBN 3-901509-47-X, ISSN 1726-9687, Vienna, Austria

DOI: $10.2507 /$ daaam.scibook.2006.06 